\title{
The effect of material position of multi-pass friction stir processing on friction stir welded AA1050/AA6082 dissimilar joints
}

\author{
Oritonda Muribwathoho ${ }^{1}$, Velaphi $\mathrm{Msomi}^{1 *}$, Ali Merdji ${ }^{2}$, and Sipokazi Mabuwa ${ }^{1}$ \\ ${ }^{1}$ Cape Peninsula University of Technology, Faculty of Engineering and the Built Environment, Mechanical Engineering Department, \\ P.O. Box 1906, Bellville, 7535, South Africa \\ ${ }^{2}$ Department of Mechanical Engineering, Faculty of Science \& Technology, University Mustapha Stambouli of Mascara, Algeria
}

\begin{abstract}
The AA1050 and AA6082 plates were used in producing dissimilar joint through friction stir welding (FSW) technique. The developed dissimilar joint was then subjected to multi-pass friction stir processing (FSP) technique. Various tests for the AA1050/AA6082 (AA1050 on the advancing side) and AA6082/AA1050 (AA6082 on the advancing side) joints were conducted on joints subjected to 1pass (1P) and 4pass (4P). The microstructural analysis showed that the increase in number of FSP passes resulted in a reduced grain size regardless of the of material position. The Vickers microhardness for AA1050/AA6082 FSPed joints increased towards AA6082 side while the microhardness for AA6082/AA1050 FSPed joints decreased towards the AA 1050 side regardless the number of the passes. The ultimate tensile strength (UTS) of AA1050/AA6082 joint increased with an increase in the number of passes while AA6082/AA1050 fluctuated between the specimens sampled from different locations of the FSPed joints.
\end{abstract}

\section{Introduction}

Friction stir welding (FSW) is a solid-state welding joining technique that was invented at The Welding Institute (TWI) of UK in 1991 and it was initially employed for aluminum alloys [1,2]. Friction stir welding (FSW) is a joining process that uses a nonconsumable rotational tool to join two plates without melting the material whereby heat is generated by friction between the rotating tool and the workpieces which in turns leads to a softening region close to the FSW tool. While the tool is traversing along the joint line, it mechanically mixes the workpieces and forges the hot and softened metal by the mechanical pressure [3]. Friction stir processing (FSP) is a technique derived from FSW [4, 5]. Friction stir processing (FSP) is a variant of friction stir welding which deals with the modification of metals' microstructure [6-8]. The operating principle of FSP is like that of the FSW technique, however, the FSP technique requires only one surface or single piece. The processed surface comes with different benefits like the increased mechanical properties, corrosion resistance, etc. [9-11]. When dealing with the FSW of dissimilar alloys, the positioning of alloy and tool offset are important parameters to reduce defects which increases mechanical properties [12,13,14-18]. Some studies suggested that if the hardest material is placed on the advancing side this can increase the heat input when welding [19-21]. Studies from several researchers show that to increase the mechanical properties of the dissimilar joint the high strength material should be positioned on the advancing side [22-24]. Cole et al. [25] studied the effect of alloy position and tool offset on FSW welding of AA 6061 and AA7075 aluminum alloys and the observed that placing the softer material on the advancing side there resulted in higher tensile strength. Lee et al. [26] analyzed the joint properties of dissimilar Al alloys formed by friction stir welding according to the fixed location of materials and based on the results concluded that the properties of the joint are strongly dependent on the alloy on the retreating side reason being that the stir zone is mainly composed on the retreating side material. Msomi and Mabuwa [27] studied the influence of materials positioning on the microstructure of the friction stir processed dissimilar joints. It was observed that the ultimate tensile strength and yield strength improves when the stronger material is positioned on the advancing side while the percentage elongation improves drastically when the low strength material is positioned on the advancing side. Sipokazi and Msomi [28] studied the effect of friction stir processing on the friction stir welded AA1050-H14 and AA6082-T6, from the study they found that positioning AA1050-H14 on the advancing side while AA6082-T6 is positioned on the retreating side, the mechanical properties were higher compared to when the weak alloy is placed on the retreating side for both FSW and FSP joints which then suggests that when welding dissimilar

\footnotetext{
* Corresponding author: msomiv@gmail.com
} 
alloys, the material positioning has an impact on the outcomes.

From literature available the effect of material position is mostly reported on friction stir welding dissimilar joints, there is little work when it comes to the effect of material position on the processing of dissimilar joint. Literature reveals that material position has various influence on mechanical properties of the dissimilar joint. This study reports on the effect of material position of multi-pass friction stir processing of friction stir welded AA1050/AA6082 dissimilar joint. The focus of this investigation will be on the $1^{\text {st }}$ pass and the $4^{\text {th }}$ pass of FSPed joints.

\section{Materials and methods}

In this study, the AA1050-H14 and AA6082-T651 were used in conducting the experiments. The chemical composition of AA1050 is 0.05 wt. $\% \mathrm{Mg}, 0.05$ wt. $\% \mathrm{Zn}$, 0.05 wt. \% V, 0.05 wt.\% Mn, 0.05 wt. \% Si, 0.4 wt.\% Fe, 0.05 wt. $\% \mathrm{Cu}$, and 99.3 wt.\% Al. The chemical composition of AA6082 was 1.1 wt.\% Mg, 0.20 wt.\% Zn, 0.25 wt.\% Cr, 0.90 wt.\% Si, 0.70 wt.\% Mn, 0.50 wt.\% Fe, 0.10 wt.\% Cu+Ag, and 96.25 wt.\% Al. The dissimilar aluminum plates were cut into the necessary sizes to allow the plates to match the backplate of the semi-automated milling machine. The dimensions of each plate used for FSW and FSP were $260 \times 52 \times 6 \mathrm{~mm}$. The FSW technique was the used to fabricate the dissimilar joints i.e. AA1050/AA6082 and AA6082/AA1050 dissimilar joints. The fabricated dissimilar joints were further subjected to 1pass (1P) and 4 pass(4P) friction stir processing. The performance of the friction stir welding (FSW) is shown in Fig. 1 (a) with AA1050 on the advancing side and Fig. 1(b) depicts FSW procedure when AA6082 was placed on the advancing side. The performance of the friction stir processing (FSP) on AA1050/AA6082 is shown in Fig. 1 (c) while Fig. 1(d) shows the employment of FSP procedure on AA6082/AA1050 joint. It should be noted that the same parameters used for the FSW are the same parameters used for FSP and this is the practice that has been employed in the literature [28-30]. The welding and processing parameters used for this study are as follows: the tool rotational speed of $1200 \mathrm{rpm}$, tilt angle of $2\left(^{\circ}\right)$ and traverse speed of $1 \mathrm{~mm} / \mathrm{s}$. The high-speed steel tool of a triangular pin profile with flutes was used in performing both FSW and FSP. The $5.8 \mathrm{~mm}$ long tool pin had a diameter of $7 \mathrm{~mm}$ and the shoulder diameter of $20 \mathrm{~mm}$.

The total number of plates that were processed was 4 i.e. the 1st plate for 1-pass FSPed AA1050/AA6082, 2nd plate for 1-pass FSPed AA6082/AA1050, 3rd plate for 4-pass FSPed AA1050/AA6082 and 4-pass FSPed AA6082/AA1050. The waterjet cutting technology was used for cutting the FSPed plates for various experiments. The tensile test, microstructural analysis and microhardness were the main the tests conducted in this study.

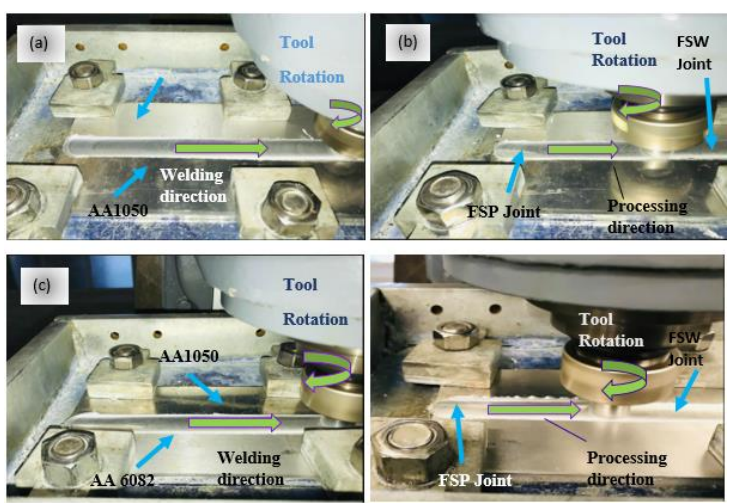

Fig. 1: (a) Friction stir welded plate with AA1050 on the advancing side, (b) Friction stir processed joint of AA1050/AA6082 (c) Friction stir welded plate with AA6082 on the advancing side and (d) Friction stir processed joint of AA6082/AA1050.

The post-tensile test specimens were further analyzed using scanning electron microscopy (SEM) to analyze the nature the of the fracture. The Hounsfield $50 \mathrm{~K}$ tensile testing machine was used to conduct the tensile tests for the purpose of this analysis. The standard ASTM-E8M-04 was used to conduct tensile test and for the design of tensile specimens. Fig. 2. (a) shows the tensile specimen schematic diagram used for this analysis. The Innova Test (Falcon 500) machine was used to perform the microhardness test with the standard ASTM E384-11. Fig. 2(b) shows the microhardness specimen schematic diagram and the sample sampling locations are shown in Fig. 2. (c). The S, M and E labels were used to mark the start, middle, and end of the FSPed joints, respectively. There is a total of 6 specimens for each pass. The Motic AE2000 microscope was used for the microstructural metallographic examination. The cross-section surfaces of the friction stir processed joints were grounded, polished, then etched. The modified Weck's reagent and Keller's reagent etchants were used for the microstructural analysis. ImageJ software with the ASTM E112-12 standard was used to calculate the average grain size.
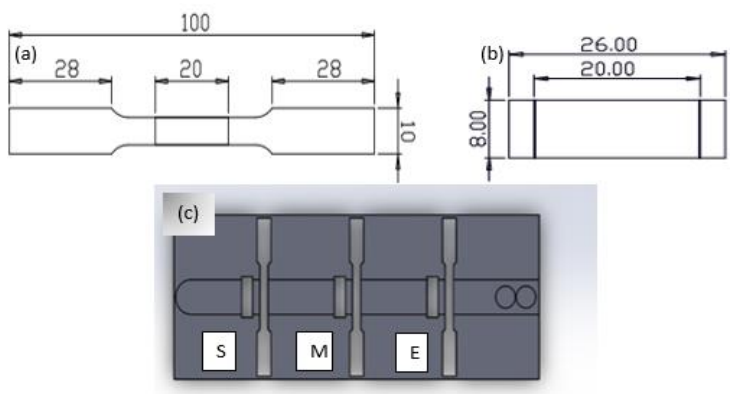

Fig. 2: (a) Specimen for tensile test testing, (b) Specimen for microhardness testing (all dimensions are in $\mathrm{mm}$ ), and (c) Specimen sampling positions for each joint. 


\section{Results and discussions}

\subsection{Metallographic morphology}

Fig. 3 (a)- (f) displays the macrographs of the specimens for 1P friction stir processed (FSPed) joints. Fig. 3 (a), (b), and (c) displays the microstructure for 1P FSPed AA1050/AA6082 with the specimens sampled from S, $\mathrm{M}$ and E. Fig. 3 (d), (e), and (f) displays the microstructure for 1P FSPed AA6082/AA1050 with the specimens sampled from the $\mathrm{S}, \mathrm{M}$ and $\mathrm{E}$. The macrographs of the specimens for 4P FSPed joints are shown in Fig. 4 (a) - (f). Fig. 3.2 (a), (b), and (c) show the microstructure for 4P FSPed AA1050/AA6082 with the specimens sampled from S, M and E. Fig. 4 (d), (e), and (f) show the microstructure for 4P FSPed AA6082/AA1050 with the specimens sampled from S, $\mathrm{M}$ and $\mathrm{E}$. The respective standard deviations and their respective mean grains of the surfaces depicted in Fig. 3 and Fig. 4 are illustrated in Fig. 5. The mean grain size of 1P FSPed AA1050/AA6082 joint ranged between $14.84 \mu \mathrm{m}$ and $19.18 \mu \mathrm{m}$ with the mean grain size of $1 \mathrm{P}$ FSPed AA6082/AA1050 joint ranging between 11.84 $\mu \mathrm{m}$ and $13.12 \mu \mathrm{m}$. The mean grain size of 4P FSPed AA1050/AA6082 joint ranged between $8.61 \mu \mathrm{m}$ to $16.62 \mu \mathrm{m}$ with the mean grain size of $4 \mathrm{P}$ FSPed AA6082/AA1050 joint ranging between $5.20 \mu \mathrm{m}$ and $2.66 \mu \mathrm{m}$. It is worth noticing that there was a reduction in the mean grain sizes as the number of passes were increased. As a result of recrystallization and rerecrystallization occurring it is worth noticing that there was grain size refinement as the number of FSP passes were increased [31,32].
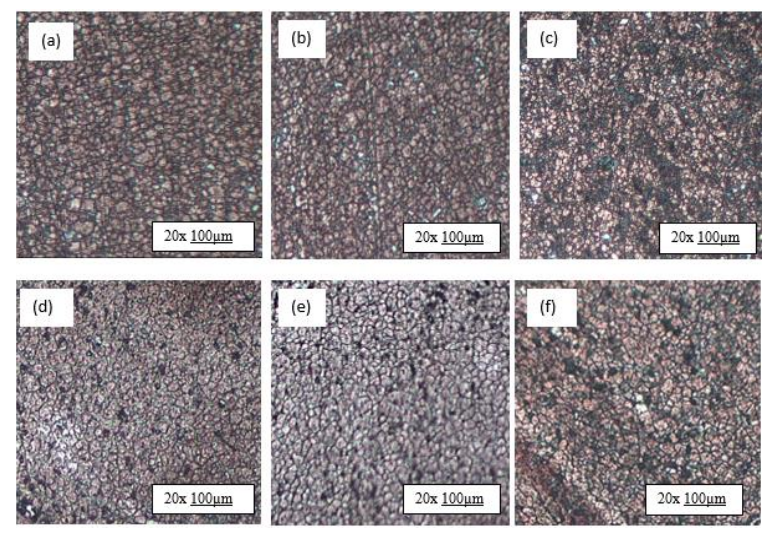

Fig. 3: Micrographs; 1P FSPed AA1050/AA6082 (a) Start, (b) Middle, (c) End; 1P FSPed AA6082/AA1050 (d) Start, (e) Middle, (f) End.

\subsection{Tensile properties}

The fractured surface for the post tensile for the specimens is shown in Fig. 6 (a)- (d). The post tensile fractures for the 1P specimens are shown in Fig. 6 (a) for 1P AA1050/AA6082 and in Fig. 6 (b) for 1P AA6082/AA1050. The post tensile specimen for 4P AA1050/AA6082 is shown in Fig. 6 (c), while post tensile specimen for 4P AA6082/AA1050 is shown in Fig. 6 (c).
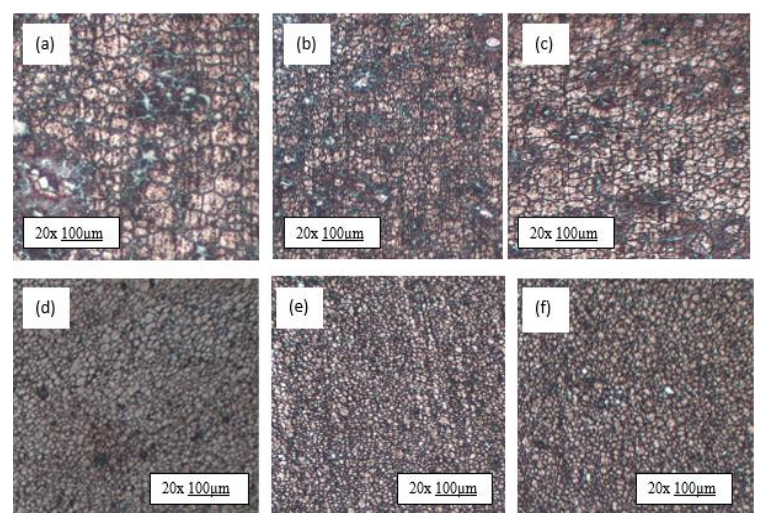

Fig. 4: Micrographs; 4P FSPed AA1050/AA6082 (a) Start, (b) Middle, (c) End; 4P FSPed AA6082/AA1050 (d) Start, (e) Middle, (f) End.

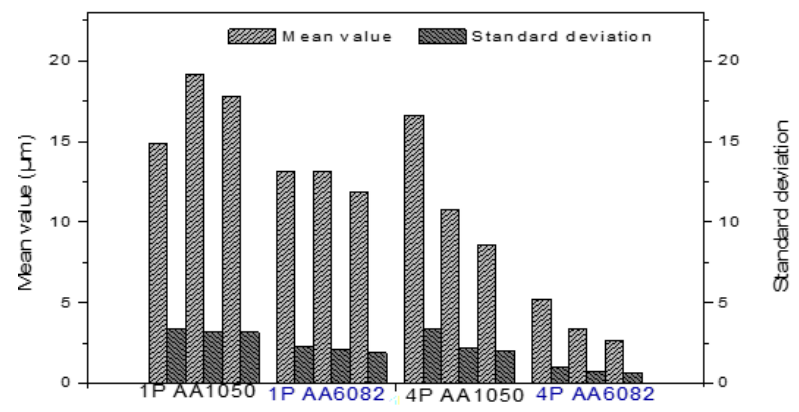

Fig. 5: Mean grain size and standard deviation

The stress-strain curves are shown in Fig. 7 (a)- (d) and Fig. 8 shows their respective tensile properties. For $1 \mathrm{P}$ AA1050/AA6082, the percentage elongation increased with a decrease in the UTS while for the 1P AA6082/AA1050 the percentage elongation was decreasing with the UTS fluctuating. The percentage elongation decreased with an increase in the UTS for the 4P AA1050/AA6082, while for the 4P AA6082/AA1050 the percentage elongation was decreasing with the UTS fluctuating. For the 1P FSPed AA1050/AA6082 joint, the maximum UTS was 79.7 $\mathrm{MPa}$ and for the 1P FSPed AA6082/AA1050 joint, it was 74.7 MPa. The maximum UTS for the 4P FSPed AA1050/AA6082 joint was $86.1 \mathrm{MPa}$ and that of the 4P FSPed AA6082/AA1050 joint was $69.5 \mathrm{MPa}$. It was observed that regardless of the material position, the percentage elongation for both $1 \mathrm{P}$ and $4 \mathrm{P}$ was greater than 100 percent relative to that of both AA1050 and AA6082 base materials and this is attributed to microstructural arrangement that was influenced by material positioning [33].

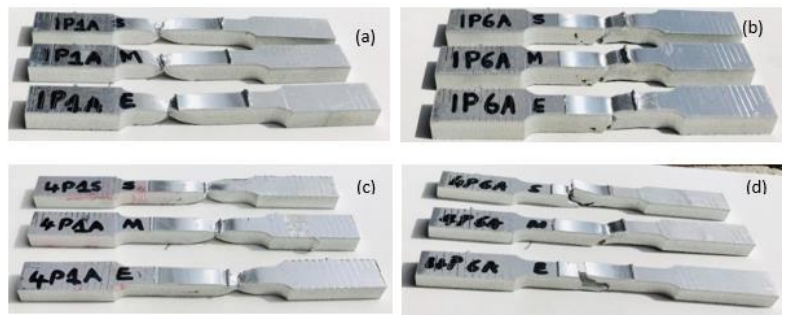

Fig. 6: Post tensile specimens (FSPed); (a) 1Pass

AA1050/AA6082; (b) 1 Pass AA6082/AA1050 (c) 4 Pass A1050/AA6082 and (d) 4 Pass AA6082/AA1050. 

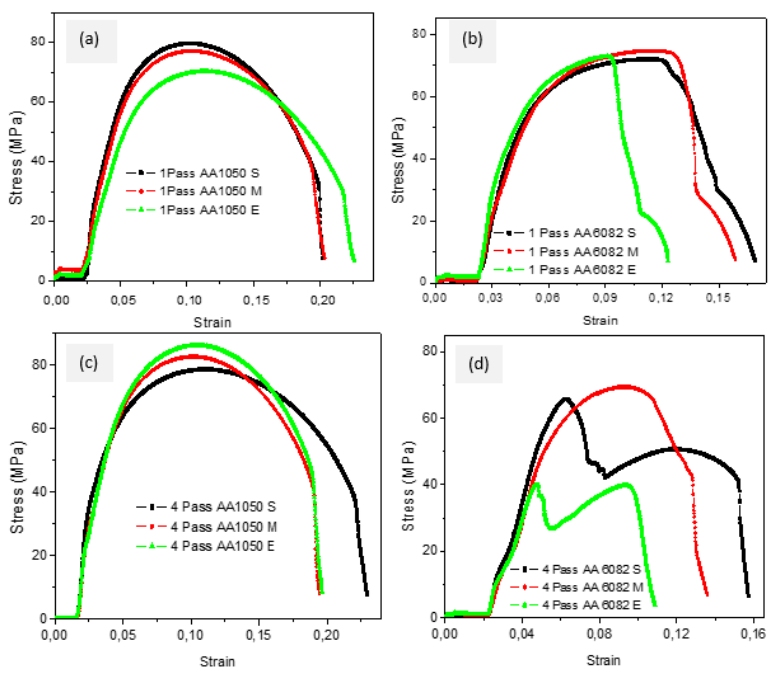

Fig. 7: Stress Strain curves (FSPed) (a) 1 Pass AA1050/AA6082; (b) 1 pass A6082/AA1050; (c) 4 Pass AA1050/AA6082 and (d) 4 Pass AA6082/AA1050.

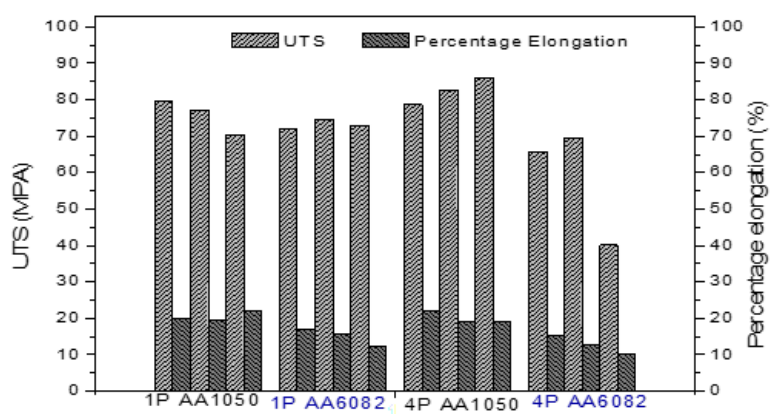

Fig. 8: Tensile properties for each pass from S, M and E.

\subsection{Fracture morphology}

Fig. 9 and 10 depict the fracture morphology of $1 \mathrm{P}$ and 4P FSPed joints. The tensile surface morphology for specimens sampled from $\mathrm{S}, \mathrm{M}$ and $\mathrm{E}$ for $1 \mathrm{P}$ FSPed joints are shown in Fig. 9 (a) - (f). Fig. 10 (a) - (f) shows the tensile surface morphology for the specimens sampled from $\mathrm{S}, \mathrm{M}$ and $\mathrm{E}$ for $4 \mathrm{P}$ FSPed joints. The morphology for 1P FSPed AA1050/AA6082 joint is shown in Fig. 9 (a)- (c) while the morphology for 1P FSPed AA6082/AA1050 joint is shown in Fig. 9 (d) - (f). The morphology for 4P FSPed AA1050/AA6082 joint is shown in Fig. 10 (a) - (c) while Fig. 10 (d) - (f) shows the morphology for 4P FSPed AA6082/AA1050 joint. It was noted that the morphology of 1P AA1050/AA6082 and the morphology of 4P AA1050/AA6082 were characterized by dimples and micro voids. The presence of dimples along with the micro voids is an indication of ductile failure mode [34-36]. Fig. 9 (c)- (f) and Fig. 10 (c) and (f) were characterized by the presence of riverlike fractured surfaces. It was noticed that there was a ductile failure. Fig. 10 (d) was characterized by the presence of dimples.
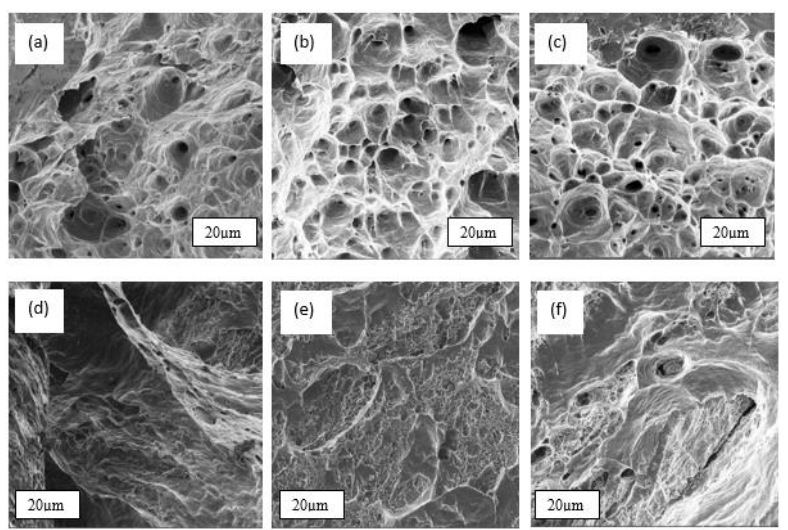

Fig. 9: SEM tensile FSPed: 1P AA1050/AA6082; (a) Start, (b) Middle. (c) End; 1P AA6082/AA1050; (d) Start, (e) Middle, (f) End.
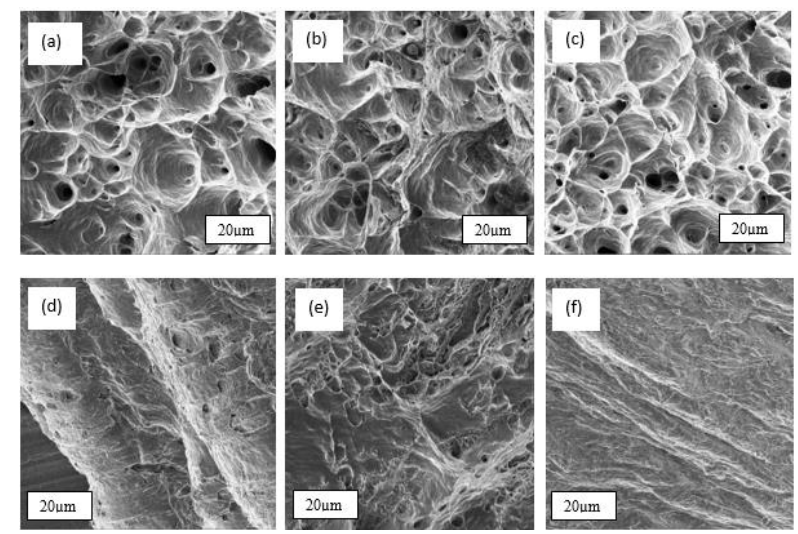

Fig. 10: SEM FSPed: 4P AA1050/AA6082; (a) Start, (b) Middle. (c) End. 4P AA6082/AA1050; (d) Start, (e) Middle, (f) End.

\subsection{Microhardness analysis}

The Vickers microhardness outcomes for the FSPed joints are shown in Fig. 11. Fig. 11 (a), (b), (c), and (d) demonstrate the microhardness profile of the specimens sampled from the $\mathrm{S}, \mathrm{M}$ and $\mathrm{E}$ of $1 \mathrm{P}$ joints and $4 \mathrm{P}$ joints. Fig. 11 (a) displays the microhardness results for the $1 \mathrm{P}$ FSPed joint with AA1050 on the advancing side, and the microhardness results for 1P FSPed joint with AA6082 on the advancing side is shown in Fig. 11 (b). Fig. 11 (c) displays the microhardness results for the 4P FSPed joint with AA1050 on the advancing side, and the microhardness results for 4P FSPed joint with AA6082 on the advancing side is shown in Fig. 11 (d). The maximum SZ microhardness was measured to be 72.84 HV for the 1P AA1050/AA6082 joint and the maximum SZ microhardness was measured to be $66.67 \mathrm{HV}$ for $1 \mathrm{P}$ AA6082/ AA1050 joint. For the 4P joints, the maximum SZ microhardness was measured $62.45 \mathrm{HV}$ for the $4 \mathrm{P}$ AA1050/AA6082 joint and the maximum SZ microhardness was measured to be $64.29 \mathrm{HV}$ for the $4 \mathrm{P}$ AA6082/ AA1050 joint. For all the FSPed joints, the microhardness at the TMAZ on the advancing side is less relative to that of the retreating side when AA1050 is placed on the advancing side. The microhardness at the TMAZ on the advancing side is higher for all the FSPed joints when AA6082 is placed on the advancing side as compared to the one on the retreating side, the 
same pattern is observed by Cavaliere et al [37]. It should be noted that the microhardness for AA1050/AA6082 FSPed joints was increasing towards the AA6082 and the microhardness for AA6082/AA1050 FSPed joints were decreasing towards the AA 1050 regardless of the number of the passes.
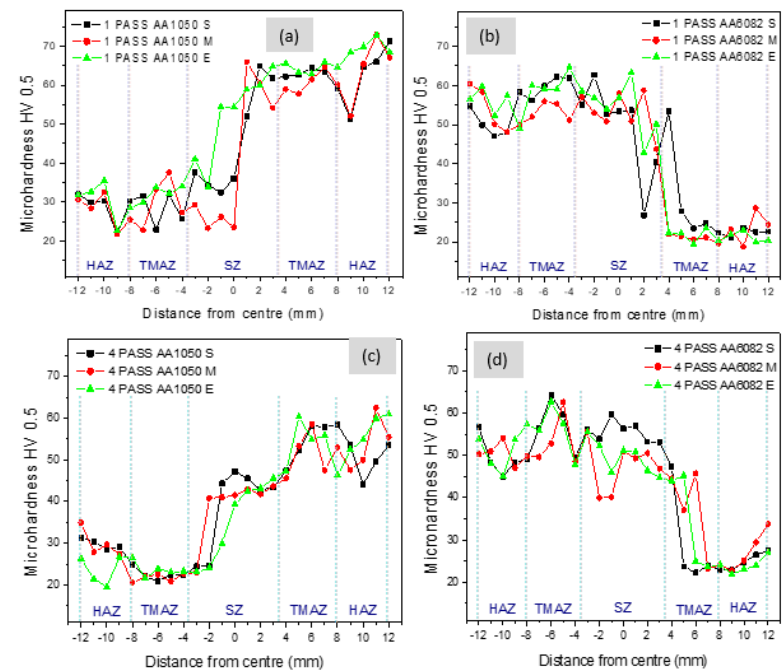

Fig. 11: Microhardness results: (a) 1 pass AA1050/AA6082, (b) 1 pass AA6082/AA1050, (c) 4 pass AA1050/AA6082 and (d) 4 pass AA6082/AA1050

\section{Conclusion}

The effect of material position of multi-pass friction stir processing on friction stir welded AA1050/AA6082 of dissimilar joints was studied. Results have been evaluated for 1P AA1050/AA6082, 1P AA6082/AA1050, 4P AA1050/AA6082 and AA6082/AA10502P FSP were analyzed. Conclusions were made on the basis on the results archived; the findings are as follows:

- The grain sizes were decreased as the number of passes was increased irrespective of the material position for microstructural study.

- The ultimate tensile strength revealed when AA1050 was placed on the advancing side the UTS was increasing as number of FSP passes were increased. When AA6082 was positioned on the advancing side the UTS was fluctuating between the specimens sampled from different locations of the FSPed joints.

- The Vickers microhardness for AA1050/AA6082 FSPed joints increased towards AA6082 and the Vickers microhardness for AA6082/AA1050 FSPed joints decreased towards AA 1050 regardless of the number of passes.

The authors would like to thank Miranda Waldron of the University of Cape Town from the SEM department for use of the SEM equipment.

\section{References}

1. G.G. Yapici, I.J. Ibrahim. J. Mat. Res. Techn.,11 (2021).

2. A.K. Pandey, S.S. Mahapatra. Mat. Today: Proc. 18 (2019)

3. P. Kumar, R. Kumar, B.K. Hembram, M. Murugan, A. Arif, M. Veerababu, Mat. Today: Proc. 27 (2020)

4. H.A. Derazkola, A. Eyvazian, A. Simchi. J. Manuf. Proc., 50(2020).

5. C. Zhang, Y. Cao, G. Huang, Q. Zeng, Y. Zhu, X. Huang, N. Li, Q. Liu, J. Manuf. Proc., 49 (2020).

6. C. Zhang, G. Huang, D. Zhang, Z. Sun, Q. Liu, J. Mat. Res. Techn., 9(2020)

7. C. Zhang, G. Huang, Y. Cao, Q. Li, L. Niu, Q. Liu, Mat. Today Comm., 25(2020)

8. A.F.S. Bugarin, C.P De Abreu, M. Terada, H.G. De Melo, I. Costa, Mat. Today Comm., 25(2020).

9. M.R. Jandaghi, C. Badini, M. Pavese, J. Manuf. Proc., 57(2020).

10. Z.Z. Xu, C.Y. Liu, B. Zhang, H.F. Huang, W. Cheng, J. Manuf. Proc., 56(2020).

11. O.A. Al-Roubaiy, M.S. Nabat, A.D.L. Batako, Mat. Today: Proc., 22(2020).

12. M.O. Ikumapayi, E.T. Akinlabi, Mat. Today: Proc., 18(2019).

13. P.K. Sahu, S. Pal, S.K. Pal, R. Jain, J Mater Proc. Techn., 235(2016).

14. S.K. Dewangan, M.K. Tripathi, M.K. Manoj, Mat. Today: Proc., 27(2020)

15. S.B. Uyyala, S. Pathri, Mat. Today: Proc., 23 (2020)

16. A. Garg, M. Raturi, A. Bhattacharya,Trans. Nonf. Met. Soc. China, 29(2019)

17. P.L. Niu, W.Y. Li, D.L. Chen, J. Mat. Sc. Techn., 73(2021)

18. M. Raturi, A. Garg, A. Bhattacharya, Eng. Fail. An., 96(2019)

19. U. Dwivedi, S. Tiwari, A. Mishra, S. Das, Mat. Today: Proc., 22(2020)

20. K.P. Mehta, P. Carlone, A. Astarita, F. Scherillo, F. Rubino, P. Vora, Mat. Sc. Eng. A, 759(2019)

21. H. Mehdi, R.S. Mishra, J. Adv. Join. Proc., 1(2020)

22. S. Hassanifard, H. Alipour, A. Ghiasvand, A. Varvani-Farahani, J. Manuf. Proc., 64(2021)

23. A. Fall, H. Monajati, A. Khodabandeh, M.H. Fesh araki, H. Champliaud, M. Jahazi, Mat. Sc. Eng. A, 749 (2019).

24. K.P. Mehta, P. Carlone, A. Astarita, F. Scherillo, F . Rubino, P. Vora, Mater Sci Eng A, 759 (2019).

25. E.G. Cole, A. Fehrenbacher, N.A. Duffie, M.R. Zinn, F.E. Pfefferkorn, N.J. Ferrier. Int. J. Adv. Manuf. Techn. 71(1-4) (2014).

26. W.B Lee, Y.M. Yeon, S.B. Jung. Scr Mater 49(5) (2003) 
27. V. Msomi, S. Mabuwa, Adv. Ind. Manuf. Eng., 1(2020)

28. S. Mabuwa, V. Msomi. Mater. Today: Proc, 26 (2) (2020)

29. M. Mhedhbi, M. Khlif, C. Bradai. J. Mater. Env. Sci., 8 (8) (2017)

30. M.D. Sameer, A.B. Kumar. J. Mag. Alloys., 7 (2017)

31. [31] S.R. Sharma, Z.Y. Ma, R.S. Mishra, Scr. Mater. 51, (2004)

32. V. Msomi, N. Mbana, S. Mabuwa, Mat. Today: Proc., 26(2020)

33. J.F. Guo, H.C. Chen, C.N. Sun, G. Bi, Z, Sun, J. Wei. Mater. Des., 56(2014)

34. S. Mabuwa, V. Msomi. Mater. Today: Proc., 26 (2) (2020)

35. M. Shunmugasundaram, A.P. Kumar, L.P. Sankar, S. Sivasankar. Mater. Today: Proc., 27 (2) (2020)

36. M. Orłowska, T. Brynk, A. Hütter, J. Goli_nski, N. Enzinger, L. Olejnik, M. Lewandowska. Mater. Sci. Eng., 777 (2020)

37. P. Cavaliere, A. De Santis, F. Panella, A. Squillace, Mater. Des.,30 (3) (2009) 